\title{
O ensino do gênero discursivo curriculum vitae em cursos de tecnologia por meio de sequência didática
}

\section{The teaching of the discursive genre Curriculum Vitae in technology courses using a didactic sequence}

https://doi.org/10.34112/2317-0972a2016v34n68p107-121

\section{Viviane Dinês de Oliveira Ribeiro Bartho ${ }^{1}$ \\ Luciana Aparecida Silva de Azeredo ${ }^{2}$}

\begin{abstract}
RESUMO: Este trabalho surgiu da observação das dificuldades de leitura e escrita de alunos de cursos superiores em relação a gêneros da esfera profissional da área de tecnologia. O objetivo foi elaborar e aplicar uma sequência didática com o gênero curriculum vitae, tomando uma perspectiva discursiva a partir de Bakhtin. O gênero currículo foi selecionado conforme a demanda observada dos alunos. Resultados apontam que os procedimentos permitiram o avanço em relação a aspectos não apenas técnicos da língua portuguesa e sua gramática, mas, sobretudo, a aspectos discursivos da linguagem, como seus efeitos de sentido. Para além desses aspectos, foi possível, devido ao gênero escolhido pressupor a escrita de si, tecer reflexões junto aos alunos de modo a influenciar sua autoestima, o que configura uma missão das instituições de ensino que veem seus alunos não apenas como sujeitos empíricos, mas também como sujeitos sociais e psicológicos, enfim, sujeitos da linguagem.
\end{abstract}

Palavras-chave: Leitura e escrita de gêneros discursivos; sequência didática; curriculum vitae.

ABSTRACT: This work started from the observation of higher education students' reading and writing difficulties in relation to genres in the professional sphere of technology. The

1. Instituto Federal de Educação, Ciência e Tecnologia de São Paulo, Campos do Jordão, SP, Brasil.

2. Fundação Universitária Vida Cristã, Pindamonhangaba, SP, Brasil. 
objective was to develop and implement a didactic sequence for a curriculum vitae, based on Bakhtin's discursive perspective. This genre was selected according to the observation of students' necessities and demands. Results show that the procedures promoted the improvement not only in the technical aspects of the Portuguese language and its grammar, but above all in the discursive aspects of language, such as the effects of the meanings. In addition to these aspects, it was possible to assume the writing of the self and to engage students in reflective practices in order to influence their self-esteem, which is one of the missions of educational institutions that see their students not only as empirical subjects, but also social and psychological subjects, finally, language subjects.

KEYWORDS: Reading and writing genres; didactic sequence; curriculum vitae.

\section{INTRODUÇÃO}

O tema deste artigo foi o desenvolvimento da leitura e da escrita. Para tanto, delimitou-se o trabalho do gênero discursivo curriculum vitae com alunos de cursos de tecnologia de instituições de ensino superior da região do Vale do Paraíba, São Paulo.

Cabe mencionar que o gênero discursivo curriculum vitae foi incluído no programa de disciplinas intituladas "Comunicação oral e escrita" e "Comunicação e expressão" devido ao fato de que os alunos, normalmente, solicitam ao professor de tais disciplinas auxílio para inserção e/ou recolocação no mercado atual, em especial no momento socioeconômico que temos vivenciado em nosso país.

O objetivo foi aplicar, segundo orientações de Nascimento, Deus e Oliveira (2013), uma sequência didática do gênero escolhido, a fim de levar os alunos, por meio de cada procedimento, à autonomia de leitura e produção de um texto coeso e coerente, o qual, no presente caso, por envolver a escrita de si, passava por aspectos não apenas técnicos da língua portuguesa e sua gramática, mas, sobretudo, por aspectos psicológicos, relacionados a cada sujeito participante. A sequência didática aqui relatada faz parte de um conjunto que engloba outras três sequências que abordam os seguintes temas/gêneros: redação em processos seletivos, entrevista de emprego e dinâmica de grupo. Neste artigo, será descrita apenas a sequência elaborada para a leitura e escrita de currículos.

A abordagem do currículo como gênero do discurso pressupõe uma concepção da língua como ideológica, sócio-histórica e dialógica, nos moldes do pensamento bakhtiniano. Nesse sentido, era preciso compreender os possíveis efeitos de sentido que as informações do currículo e os modos como elas eram dispostas e articuladas 
poderiam provocar, tendo em vista os interlocutores, o contexto em que o texto seria entregue, as intenções envolvidas, as imagens suscitadas etc.

Compreender a língua por seu aspecto discursivo e considerar as sequências didáticas no ensino da leitura e da produção textual podem constituir formas positivas de trabalho em sala de aula, como pôde ser observado no caso aqui relatado.

Este artigo está organizado em três seções, a saber: 1. a sequência didática no desenvolvimento da leitura e da escrita, em que são elucidadas, em linhas gerais, ideias acerca do ensino da língua e a proposta da metodologia das sequências didáticas, e também são expostas características essenciais dessas sequências; 2. aspectos da teoria de Bakhtin para o trabalho com gêneros do discurso, em que são discutidos pontos importantes e centrais do pensamento de Bakhtin, para que a abordagem da leitura e da escrita em sala de aula tenha realmente um fundamento discursivo; por fim, 3. descrição da sequência didática de leitura e produção de Curriculum Vitae, seção na qual é descrita a sequência didática de trabalho com o gênero "currículo" com alunos de cursos de tecnologia. $\mathrm{O}$ relato desta pesquisa finaliza-se com Algumas Considerações, em que se apresentam impressões e observações do processo desenvolvido.

\section{A Sequência Didática no desenvolvimento da leitura e da escrita}

O ensino de português passou por várias mudanças ao longo da História. Inicialmente, ensinava-se apenas a Gramática Normativa, depois, surgiram as teorias da comunicação e, mais recentemente, os gêneros do discurso assumiram lugar de destaque. No Brasil, os Parâmetros Curriculares Nacionais - PCN (1998), embora se restringindo ao ensino básico, recomendam priorizar o uso da linguagem e o desenvolvimento de novas habilidades linguísticas nos alunos, em especial no que tange à Norma Culta (NC) (BUENO, 2011); recomendações estas que podem ser consideradas para outros níveis de ensino.

A teoria de gêneros do discurso, apesar de parecer recente, remonta à Grécia Antiga, tendo passado pela Retórica, pela Literatura e, por último, pela Linguística. Houve, ao longo da História, várias formas de classificar os textos. Na década de 1960, Jakobson propôs as tipologias funcionais e, 30 anos mais tarde, apareceram as tipologias cognitivas de Adam e também o conceito de gênero de Bakhtin e as tipologias enunciativas de Bronckart. Nas duas últimas teorias, nas quais se embasaram Scheneuwly e Dolz (2007) para a elaboração de orientações didáticas para o 
ensino da leitura e da produção dos gêneros em ambiente escolar - as sequências didáticas -, os gêneros são um instrumento tanto de adaptação quanto de inserção social que, segundo os $\mathrm{PCN}$, pode auxiliar na formação de cidadãos críticos e mais participativos na dinâmica social (BUENO, 2011)

Dolz e Scheneuwly (2004 apud BUENO, 2011) propuseram um modelo didático que visa trabalhar as características ensináveis de um dado gênero para proporcionar aos alunos domínio da escrita e da leitura de tal gênero. $O$ cerne dessa proposta pedagógica é o trabalho com projetos que possibilitam uma recriação das condições de produção e circulação do gênero. Resumidamente, as sequências didáticas apresentam três partes:

A. Produção inicial, com base nos conhecimentos prévios dos alunos e que servirá de base para a elaboração de atividades e módulos didáticos que atuem na Zona de Desenvolvimento Proximal (ZDP) dos alunos, termo cunhado primeiramente por Vygotsky (1987);

B. Análise de bons exemplares do gênero em estudo;

C. Produção final, na qual os alunos podem fazer uma autorreflexão sobre seu progresso, e o professor pode diagnosticar o que ainda falta para aprender.

Segundo Gonçalves (2009), as atividades da sequência didática (SD) devem levar os alunos a se apropriarem de determinado gênero e devem contemplar cinco elementos:

A. Definição geral do gênero;

B. Parâmetros do contexto de comunicação;

C. Conteúdos específicos;

D. Estrutura textual global;

E. Operações da linguagem e suas marcas linguísticas.

$O$ autor ainda ressalta que a difícil tarefa de escolher o que ensinar ou não deve partir da análise da produção inicial dos alunos, mapeando suas capacidades de linguagem, para que o professor possa agir como mediador, produzindo uma SD capaz de intervir na ZDP do aluno.

No que tange à correção, deve-se ir além da visão tradicional que abarca apenas correções pontuais normalmente relativas ao uso da NC, pois, segundo Gonçalves 
(2009), esse tipo de correção promove pequenos avanços na capacidade escrita dos alunos. Propõe-se a revisão interativa, com o auxílio ou não de uma lista de constatações e a refacção como parte integrante do processo, ou seja, a avaliação de um texto é calcada na comunicação e na troca entre aluno-aluno e aluno-professor. Dentre as vantagens da utilização da lista de constatações, o autor salienta sua função de instrumento autorregulador da aprendizagem, por meio da comparação da produção inicial com a nova produção, com base nas atividades/módulos da SD, para facilitar não só a refacção do texto, mas também a assimilação das características do gênero em questão.

Em suma, uma SD visa levar os alunos a dominarem determinado gênero passo a passo, partindo de seus conhecimentos prévios e dos níveis que eles ainda precisam dominar. Ela envolve a leitura e a escrita, mas também a oralidade, promovendo o trabalho em grupo, no qual há troca de conhecimentos e auxílio mútuo, tornando a aprendizagem mais significativa para os alunos, preparando-os para atuar na dinâmica social, ou seja, para serem cidadãos mais ativos, participativos e críticos.

Vale aqui salientar que pensamento e leitura críticos são indissociáveis para Taglieber (2000), ou seja, ler criticamente implica pensar criticamente. A autora define pensamento crítico como um exame cuidadoso da solução proposta para um problema ou questão, com o intuito de determinar seus pontos fracos e fortes, fazendo uma avaliação ou uma espécie de julgamento. Pensar criticamente envolve prever resultados, formular questões e responder ao texto, aplicando suas próprias crenças e valores, de modo a decidir em que acreditar e o que fazer. É por meio do pensamento crítico que o leitor determina quais interpretações são ou não consistentes com a evidência textual e seu conhecimento prévio. Taglieber (2000) ainda salienta que é necessário não confundir compreensão, ligada ao entendimento dos sentidos, com a leitura crítica, que envolve avaliar os sentidos.

Dentro dessa perspectiva de leitura, Taglieber (2000) e Oliveira (2000), com base em Barnes (1979), comentam que, para que o pensamento e a leitura críticos sejam desenvolvidos, é necessário ajudar os alunos a organizar, a desenvolver e a expressar suas ideias por meio dos quatro tipos de pergunta, a saber:

- Questões cognitivas, baseadas na memória: 1 ) palavras-chaves: quem, o que, onde e quando; 2) operações cognitivas envolvidas: nomear, definir, identificar, designar e respostas de sim ou não. 
O ensino do gênero discursivo curriculum vitae em cursos...

- Questões convergentes: 1) palavras-chaves: por quê, como e de que forma; 2) operações cognitivas envolvidas: explicar, apontar relações, comparar e contrastar.

- Questões divergentes: 1) palavras-chaves: imagine, suponha, se, você pode criar, quais são as consequências? etc.; 2) operações cognitivas envolvidas: prever, hipotetizar, inferir e reconstruir.

- Questões de avaliação: 1) palavras-chaves: defenda, justifique, julgue, o que você acha?, qual a sua opinião?; 2) operações cognitivas envolvidas: atribuir valor, julgar, defender e justificar escolhas.

De acordo com Taglieber (2000), todos os quatro tipos de perguntas são importantes e devem ser realizados na sequência em que são apresentados, uma vez que considera os dois primeiros tipos como pré-requisitos para os dois últimos.

No ensino tecnológico, as ementas dos cursos costumam privilegiar os gêneros empresariais da esfera organizacional, como ata, relatório, entre outros. Muitas vezes, toma-se por base para preparação das aulas a referência bibliográfica da ementa, que tem como fontes manuais de redação comercial e oficial. A esse respeito, Nascimento, Deus e Oliveira (2013) alertam que, para além dos simples procedimentos técnicos, da repetição de modelos, o mercado atual cobra que os alunos sejam empreendedores, proativos, reflexivos, capazes de executar e analisar suas ações, entre outras habilidades.

Para os autores, o trabalho com gêneros discursivos visa ao desenvolvimento da capacidade de produzir gêneros de maneira efetiva, adequando-os às necessidades reais de uso da linguagem no ambiente institucional. Além disso, devem-se criar oportunidades não apenas para o uso da linguagem como instrumento para produção de textos ou construção do conhecimento, mas também para ensinar os alunos a melhor lidar com esses gêneros. Afinal, não existe uma forma única, perfeita e ideal que sirva para todos os contextos, interlocutores e intenções, mas, sim, uma forma mais adequada/adaptada às intenções dos interlocutores em dada situação de comunicação.

Ainda segundo Nascimento, Deus e Oliveira (2013), a concepção normativa e estruturalista da língua constante nos manuais e o princípio da objetividade e impessoalidade no qual eles se baseiam, por si sós, não se sustentam mais teoricamente. Além disso, os autores salientam que tal concepção e tal princípio, comprovadamente, não trazem resultados eficazes para se produzir um bom texto, pois o essencial é a adequação dele às intenções do sujeito no uso real da linguagem, e isso só é possível se o escrevente for constituído de uma concepção de língua que leve 
em conta aspectos não apenas linguísticos (palpáveis e visíveis), mas, sobretudo, contextuais, históricos e culturais para a produção de sentidos.

\section{Aspectos da teoria de BaKhtin para o trabalHo COM GÊNERos DO DISCURSO}

A fim de que o trabalho com gêneros do discurso, recomendado pelos PCN, esteja efetivamente em concordância com as ideias de Bakhtin, teórico que os definiu, é necessário retomar alguns princípios norteadores de seu pensamento.

Segundo Faraco (2006), Bakhtin atribuiu grande importância à linguagem e ao componente axiológico (valorativo) intrínseco ao ser humano, componente esse que se constrói na relação de alteridade, isto é, o mundo, em relação ao eu e ao outro, ganha valores diferentes, é significado e interpretado conforme um quadro axiológico a partir do qual cada um orienta seus atos; logo, é no plano da alteridade que o sujeito atribui sentidos ao mundo ao seu redor. Faraco (2006) esclarece que, de acordo com esses postulados, viver é tomar posição axiológica, é posicionar-se em relação a valores, e vivemos em um mundo saturado de valores, no qual nossos atos são gestos axiologicamente responsivos. Nesse sentido, nenhum enunciado pode ser neutro, pois emerge necessariamente de um contexto cultural já saturado de valores sócio-históricos.

A partir disso, Bakhtin (2006) entende a linguagem não apenas por uma perspectiva linguística, que é relevante, mas insuficiente, por enfocar o enunciado exclusivamente como um fenômeno da língua desvinculado do contexto material e situado de realização. A linguagem, apenas pela perspectiva linguística, é indiferente às dimensões axiológicas. Para o autor, a palavra, o signo linguístico, tem seu aspecto concreto-palpável (morfossintático e fonológico), seu aspecto semântico e seu aspecto axiológico (tom avaliativo). Logo, uma leitura verdadeiramente crítica precisa ir além do aspecto linguístico dos signos, além da gramática tradicional e suas nomenclaturas, e compreender o enunciado em todo o seu contexto produzido e recebido, que é sempre saturado por valores.

Além disso, na leitura, é preciso que se observe o movimento dialógico do qual todo gênero faz parte. Para Bakhtin (2003), o enunciado é social, ou seja, reflete e refrata valores sócio-historicamente construídos; ele é uma réplica ao já-dito e também provoca uma réplica a ser dita (já solicitada e prevista), e essa rede de discursos que respondem a outros e possibilitam outros configura a dialogia 
(BAKHTIN, 2003). A dialogia não é um ato passivo, um mero reconhecimento, mas uma resposta ativa que significa uma tomada de decisão diante do enunciado. Dessa forma, ler criticamente é assumir esse jogo dialógico de forma ativa. Para haver dialogia, o material linguístico precisa ser observado na esfera do discurso, ou seja, ser transformado em enunciado concreto, no qual se assume a posição de um sujeito social, capaz de fazer réplicas ao dito, confrontar posições, concordar com a palavra do outro, discordar dela, confirmá-la, ampliá-la. Para tanto, o conhecimento, por si só, da nomenclatura gramatical não é suficiente para que se compreendam os enunciados em seu processo dialógico e se assuma uma posição valorativa diante deles.

Constituído da concepção de linguagem proposta por Bakhtin, o professor pode passar a desenvolver a leitura e a escrita por meio de gêneros discursivos, os quais apresentam as seguintes características:

A. Funções sociocomunicativas: relacionadas às circunstâncias e às intenções;

B. Conteúdo temático: a escolha do gênero, tendo por base a intenção;

C. Estilo verbal: recursos linguísticos;

D. Estrutura composicional: relativamente estável, mas passível de escolha e adaptação.

Trabalhando com gêneros em uma SD, Nascimento, Deus e Oliveira (2013) propõem esse processo em quatro momentos:

A. Apresentação da situação por meio de seminários realizados pelos alunos;

B. Primeira produção;

C. Módulos didáticos com intuito de fornecer condições para superação das dificuldades levantadas;

D. Produção final seguida da avaliação com base em uma atitude responsável, humanista e profissional.

Antes de passarmos à seção seguinte, na qual serão descritos a atividade e os momentos vivenciados durante sua realização, cabe mencionar que optamos pela pesquisa-ação, método de pesquisa no qual o pesquisador não apenas observa uma dada situação, mas também atua diretamente sobre ela. 
Descrição da SEquênCIA didática de leitura e produÇão de Curriculum Vitae

A sequência didática a ser apresentada foi aplicada a alunos de cursos de tecnologia de instituições de ensino superior da região do Vale do Paraíba, São Paulo, nos anos de 2015 e 2016. Como primeira etapa, foi realizado um levantamento dos conhecimentos prévios dos alunos, solicitando-lhes que dissessem quais acreditavam serem os aspectos positivos e negativos para elaboração de um curriculum vitae (CV), elencando-os no quadro branco. Dentre os aspectos levantados pela sala, constaram a quantidade máxima de páginas, a veracidade de algumas informações, a atenção à gramática e à ortografia. Foi também realizado o seguinte exercício de verdadeiro ou falso com o uso de projetor:

( ) É fundamental colocar os números dos documentos (RG, CPF etc.)

( ) Fotos, pretensão salarial e referências não são obrigatórios.

( ) A seção "cursos" não precisa conter a carga horária e o ano em que foi realizado o curso.

( ) Objetivos como "Concorrer a vaga conforme minhas qualificações e necessidades da empresa” são preferíveis.

( ) A correção gramatical e o layout (apresentação) do CV não contam tanto quanto as experiências e os cursos.

( ) Na seção idiomas, basta mencionar o nível linguístico.

( ) Viagens ao exterior (trabalho, estudo ou lazer) não devem ser mencionadas.

Foi solicitado aos alunos que, em pares, discutissem as frases e anotassem as repostas no caderno. A correção foi feita não apenas com a constatação de quais frases eram verdadeiras ou falsas, mas também com o questionamento dos porquês de tal resposta e o que incluir ou não e com justificativa para as respostas. Tal procedimento está em consonância com o proposto por Taglieber (2000) e Oliveira (2000), já mencionados aqui, no que tange ao desenvolvimento do pensamento crítico, e está alinhado à reflexão discursiva acerca dos fatores que podem interferir na produção de sentidos.

Como segundo passo, foi projetada a reportagem "Especialista em RH dá dicas de como montar um currículo", apresentada no SBT Interior³. Os alunos deveriam observar quais itens não havíamos abordado até então. Para encerrar a aula, foi solicitado

3. Disponível em: <https://www.youtube.com/watch?v=8aXPoApslGs>. Acesso em: 02 fev. 2015. 
aos alunos que apresentassem seus currículos impressos na próxima aula. Para os que ainda não tinham um currículo (muitos estavam em busca do primeiro emprego), foi solicitado que o elaborassem da forma como acreditavam que deveria ser feito, com base na introdução discutida em sala e na consulta a colegas e parentes.

Como fonte de consulta e estudos, foram disponibilizados por e-mail reportagens e artigos ${ }^{4}$ sobre o tema para leitura prévia. Vale ressaltar que, entre os materiais enviados, havia modelos de currículos recomendados por especialistas em Recursos Humanos para promover o acesso a exemplares do gênero em estudo. Na aula seguinte, de posse dos currículos e depois de um bate-papo com os alunos sobre as leituras, o resumo aqui transcrito a seguir, usado como uma lista de constatações, foi apresentado e comentado pela professora. Os alunos deveriam fazer apontamentos em seu próprio CV com base nas orientações e nos estudos feitos em casa.

\section{Dicas para elaboração de um bom currículo - resumo}

- O currículo deve conter no máximo duas páginas. Dever ser breve, objetivo e verdadeiro.

- O layout deve ser limpo e claro. Trabalhe bem as margens e os espaçamentos.

- O uso de cores, de fontes variadas e de letras pequenas deve ser evitado. Destacar informações com negrito, itálico ou sublinhado.

- Deve-se incluir foto apenas se for solicitado e/ou se acreditar que vai auxiliar. Mas lembre-se: ela deve ser clara e com um sorriso.

- Atenção à gramática, em especial ao paralelismo. É mais adequado usar substantivos nas atribuições, nos resultados e nas qualificações.

- CV cronológico pode "ressaltar" crescimento e continuidade. CV funcional é preferível para pessoas que mudaram de emprego e/ou carreira com frequência, pois, apesar de ressaltar as habilidades e talentos, é mais inflexível por ser elaborado para vagas específicas.

4. Disponíveis em: <http://g1.globo.com/jornal-hoje/saladeemprego.html>. Acesso em: 02 fev. 2015. 


\section{Layout básico}

\section{Nome completo}

\section{Dados pessoais}

Nome, endereço, telefones e e-mail; não é necessário inserir números dos documentos.

\section{Objetivo}

1 linha = cargo ou área; evitar objetivos muito genéricos como "Concorrer a vaga conforme minhas qualificações e necessidades da empresa"; ou "Marketing, Vendas, Tecnologia da Informação, Telemarketing, Administração”.

\section{Síntese de Qualificações}

Escolher as principais de acordo com a vaga; atenção ao paralelismo, dando preferência aos substantivos.

\section{Formação Acadêmica}

Curso, instituição e ano de conclusão (por ordem de importância: Pós-graduação, graduação, curso técnico/Ensino Médio)

\section{Idiomas}

Idioma e nível (não é necessário mencionar onde e quando estudou; vale mencionar certificados internacionais e cursos no exterior)

\section{Experiência Internacional}

Países e motivo da viagem

\section{Experiência Profissional}

Período; empresa; cargo e atribuições

Mencionar apenas os cinco últimos empregos

Enfatizar promoções

Apresentar as atribuições e os resultados de forma sucinta, com atenção ao paralelismo, dando preferência aos substantivos.

\section{Cursos}

Escolher os relacionados à vaga/área de atuação

Mencionar tema e instituição

\section{Informática}

Programas e ferramentas (não é necessário mencionar cursos, instituições e datas) 
O ensino do gênero discursivo curriculum vitae em cursos...

Na sequência, os alunos trocaram os currículos e analisaram o currículo dos colegas, tendo como orientação tomar como base a lista de constatações e suas notas e consultar a professora em caso de dúvidas. Nova troca foi realizada entre eles. No final da aula, foi-lhes solicitado que, com apoio nas atividades realizadas, reescrevessem seu CV. A professora esclareceu que a atividade seria pontuada como um exercício da prova bimestral, com a condição de que apresentassem a versão final no dia da referida avaliação, após a correção inicial feita, anexando a primeira versão para que se constatassem as mudanças operadas.

Foram realizadas sessões de feedback individuais, nas bibliotecas das instituições, nas quais a professora procurou levantar com os alunos pontos de melhoria nos currículos, ressaltando: a importância de omitir certos aspectos, mas não mentir sobre eles; a forma melhor de organizar as informações; o modo como eram apresentadas, por exemplo: em vez de "colocação de tomadas", indicar, como uma das atividades realizadas, o uso de "instalações elétricas residenciais e comerciais”. Alterações como essas só foram possíveis questionando-se o aluno para o entendimento de seu histórico escolar e profissional, suas habilidades e competências. As escolhas linguísticas e o modo de redação eram apontados aos alunos para que refletissem acerca dos sentidos que poderiam vir à tona e das imagens que poderiam ser construídas e projetadas, tendo em vista os objetivos dos interlocutores do contexto.

Fatos importantes de sua vida profissional e acadêmica não constavam em seus currículos, como, por exemplo, prêmios estudantis, participação com premiação em olimpíadas, trabalho voluntário, cursos e palestras, entre outros. A professora apontou a importância de valorizarem conquistas e participações dessa natureza, visto que poderiam constituir um diferencial para a decisão do avaliador/recrutador.

O feedback individual foi de extrema importância para a autoestima dos alunos, em geral. Alunos que majoritariamente vieram do ensino público muitas vezes precário, alguns desempregados ou em busca do primeiro emprego, ao início do feedback, diziam à professora "eu não tenho nada para colocar no currículo"; "meu currículo é muito pobre"; "eu não tenho quase nada de cursos"; porém, na versão final do currículo, para além da conformidade com o que se espera da aprendizagem de um gênero discursivo, como elencado nas duas primeiras seções deste trabalho, foi possível trabalhar aspectos sociais e psicológicos dos alunos, estimulando-os a valorizar-se e ensinando-lhes como falar/escrever de si de forma mais assertiva e positiva. 
Cabe aqui mencionar o ensaio orteguiano de 1930, intitulado "A missão da universidade", no qual o filósofo espanhol salienta que a missão do ensino superior é, além de formar bons profissionais e fazer ciência, relacionar-se com a vida real, nela interferindo, bem como transmitir "Cultura Geral", base para que o aluno tenha certa compreensão de seu tempo e de si próprio (ORTEGA Y GASSET, 1930).

\section{Algumas considerações}

Observou-se que a elaboração e a aplicação de sequências didáticas podem contribuir para a aprendizagem dos alunos em razão de os procedimentos planejados e adotados atuarem na zona de desenvolvimento proximal deles: fazem uma espécie de ponte entre o que já sabem e o que precisam conhecer, levando em conta hipóteses que os alunos fazem sobre questões desconhecidas, verificação dessas hipóteses, comparação entre informações, reflexões acerca dos efeitos de sentido que aspectos verbais e não verbais da linguagem podem produzir em determinado gênero discursivo e contexto. Resumidamente, as $\mathrm{SD}$ e o trabalho por meio de gêneros podem contribuir para o processo de ensino da leitura e da escrita.

A abordagem discursiva por nós adotada e exemplificada neste artigo teve por objetivo promover a participação e a interação dos alunos; promover a leitura, o pensamento e o posicionamento críticos; desenvolver as competências comunicativas; tornar as aulas mais dinâmicas, menos rotineiras; possibilitar a inclusão da tecnologia e o uso de outros ambientes da instituição, como a biblioteca e os laboratórios, entre outros. Seu intuito direcionou-se para além de simplesmente passar conteúdos (gramática, ortografia, características dos gêneros discursivos etc.) aos alunos e buscou facilitar a aprendizagem, ajudá-los a aprenderem por si mesmos, a partir de textos escritos, exercícios em grupos etc., mostrando-lhes que, para que haja aprendizado, deve haver comprometimento mútuo: "professor e aluno devem contribuir para tornar a 'colaboração' [/convivência] a mais agradável possível [e para que haja aprendizado]" (BRAUER, 2012, p. 93, grifo nosso).

\section{REFERÊNCIAS}

BAKHTIN, M. M. Os gêneros do discurso. In: BAKHTIN, M. M. Estética da criação verbal. São Paulo: Martins Fontes, 2003. 
O ensino do gênero discursivo curriculum vitae em cursos...

BAKHTIN, M. M. Marxismo e filosofia da linguagem. 12. ed. São Paulo: HUCITEC, 2006.

BRASIL. Ministério da Educação. Secretaria da Educação Fundamental. Parâmetros Curriculares Nacionais: terceiro e quarto ciclos do Ensino Fundamental: Língua Portuguesa. Brasília, DF, SEF/MEC, 1998.

BRAUER, M. Ensinar na universidade: conselhos práticos, dicas e métodos pedagógicos. São Paulo: Parábola, 2012.

BUENO, L. Os gêneros jornalísticos e os livros didáticos. Campinas-SP: Mercados das Letras, 2011.

FARACO, C. A. Linguagem e diálogo: as ideias linguísticas do círculo de Bakhtin. 2. ed. Curitiba: Criar Edições, 2006.

GONÇALVES, A. V. Ferramentas didáticas e ensino: da teoria à prática de sala de aula. In: NASCIMENTO, E. L. Gêneros textuais: da didática das línguas aos objetos de ensino. São CarlosSP: Claraluz, 2009. p. 224-248.

NASCIMENTO, E. P.; DEUS, K. R. G.; OLIVEIRA, P. R. S. A produção de gêneros textuais do universo empresarial e oficial mediada por sequências didáticas. ReVEL, v. 11, n. 21, p. 26-49, 2013. Disponível em: <http://www.revel.inf.br/files/869cfib839d7eo0461731e8a7ae1ba8d.pdf>. Acesso em 12 dez. 2016.

OLIVEIRA, S. Question-asking in Brazilian Portuguese reading comprehension textbooks. Ilha do Desterro: A Journal of English Language, Literatures in English and Cultural Studies, Santa Catarina, n. 38, p. 39-56, jan./jun. 2000.

ORTEGA Y GASSET, J. La misión de la universidad. Madrid: 1930. Disponível em: <http://www. cedus.cl/files/mision_universidad.pdf $>$. Acesso em: 12 maio. 2013.

SCHENEUWLY, B.; DOLZ, J. Gêneros orais e escritos na escola. Campinas: Mercado de Letras, 2007.

TAGLIEBER, L. K. Critical reading and critical thinking: the state of the art. Iha do Desterro: A Journal of English Language, Literatures in English and Cultural Studies, Santa Catarina, n. 38, p. 15-37, jan./jun. 2000.

VYGOTSKY, L. S. Pensamento e linguagem. Tradução de Jefferson Luiz Camargo. São Paulo: Martins Fontes, 1987.

\section{SOBRE AS AUTORAS}

Viviane Dinês de Oliveira Ribeiro Bartho é licenciada em Letras - Português/ Inglês e Mestra em Linguística Aplicada (ambos pela Universidade de Taubaté). É doutoranda em Filologia e Língua Portuguesa (Universidade de São Paulo). Atualmente, é professora do Instituto Federal de São Paulo.

E-mail:viviane_dines@yahoo.com.br

Luciana Aparecida Silva de Azeredo é licenciada em Letras - Português/Inglês e Mestra em Linguística Aplicada (ambos pela Universidade de Taubaté). É 
bolsista CAPES e doutoranda em Educação (Universidade São Francisco). Atualmente, é professora da Fundação Universitária Vida Cristã.

E-mail: luazeredo@gmail.com

Recebido em 31 de julho de 2016 e aprovado em 19 de dezembro de 2016. 